\title{
Migração, Transfomações Sociais e Reforma Eclesial Pastoral jesuítica e scalabriniana no Brasil da Primeira República
}

\author{
Maurizio Russo *
}

Este artigo representa a primeira parte de uma pesquisa in fieri que, grosso modo, se desenvolve cronologicamente da Primeira República brasileira até a Primeira Guerra Mundial, coincidindo com os dois pontificados de Leão XIII e Pio X. Com a República, tem início um período de renascimento da Igreja Católica, que se concretiza num profundo processo de reorganização e reestruturação, marcado pela forte presença do imigrante.

\section{A Igreja brasileira após a Independência}

Dentre todas as novas entidades nacionais que surgiram na América Latina do século XIX, o Brasil representa uma interessante exceção, pois foi o único território que não adotou a República como forma de governo. Quando, em 1821, D. João VI de Portugal retornou à Europa, seu filho Pedro aproveitou para tomar o poder e, em 14 de setembro de 1822, se tornou imperador do Brasil, jurando sobre a bandeira fidelidade à Constituição (MECHAM, 1966, p. 262).

A Assembleia Constituinte que se reuniu em abril de 1823 foi presidida pelo bispo do Rio de Janeiro, José Caetano da Silva Coutinho. O trabalho da Assembleia produziu a Constituição de 30 de agosto de 1823 que garantia: a) liberdade de religião a todas as comunidades cristãs; b) tolerância às religiões não-cristãs, que continuavam, porém, destituídas de direitos políticos; c) reconhecimento da religião católica romana como religião do Estado; d) sustento financeiro do

* Doutor em História pela Université de Nancy 2 (France); especializado em História contemporânea da Igreja; LEI-USP. 
Estado para a religião católica romana; e) direito de padroado ao imperador, a quem era permitido arbitrar sobre a entrega dos benefícios eclesiásticos e, além disso, aprovar a entrada dos documentos papais no país (placet).

Pedro I rejeitou a proposta da Assembleia Constituinte e nomeou uma nova Assembleia, a qual elaborou a Carta Imperial de 1824. Na sua forma definitiva, a Constituição declarava "a religião católica apostólica romana" como sendo a religião oficial do Império, "tolerando" todas as outras religiões em lugares específicos de culto, que não podiam nunca ter o aspecto de igrejas. A tradição política regalista no campo eclesiástico se acentuou muito no período imperial. Em 1827, Leão XII efetuou uma tentativa de reconhecer oficialmente o régio direito de padroado com a bula Praeclara Portugalliae (de 15 de maio de 1827), mas a Assembleia Legislativa rejeitou o documento pontifical, julgando-o inútil. Os direitos do padroado eram parte integrante e constitutiva do poder monárquico e, portanto, não necessitavam nenhuma aprovação da parte do Papa, que podia somente reconhecer a natureza regalista do padroado. 0 conflito se recompôs, em parte, em 1828, quando Leão XII aceitou o status do padroado regalista, porém, sem reconhecê-lo formalmente. O poder político brasileiro se caracterizava por um liberalismo regalista que tinha, entre os seus sustentadores, numerosos expoentes do mundo eclesiástico, que defendiam a autonomia da Igreja local em detrimento do Poder Central Romano. O principal representante desse movimento foi Diego Antônio Feijó, sacerdote e deputado, que foi ministro da justiça em 1831-32, regente do Brasil de 1835 a 1837 e (em 1863) ameaçou conflagrar um movimento cismático, mas não foi apoiado pelo parlamento. Depois do movimento de independência, a posição de Roma em relação à Igreja na América Latina tornou-se extremamente difícil. O Vaticano devia, por um lado, pensar em uma estratégia diplomática para estreitar relações com os novos Estados que pretendiam herdar o padroado da coroa espanhola ou portuguesa (caso do Brasil), e, por outro lado, reorganizar a Igreja local, lutando com as múltiplas realidades eclesiásticas saídas do processo de independência latino-americano, muito mais ligadas ao poder e aos interesses locais do que ao Poder Central Romano (RUSSO, 2006).

\section{A decadência das ordens religiosas e a crise eclesiástica}

Uma importante consequência do conflito entre poder político e poder eclesiástico, no século XIX, foi a decadência das ordens religiosas brasileiras, que perdurou até o fim do século. Em 1824, os Agostinianos da Bahia foram submetidos a uma política de fortes restrições, fato que provocou graves problemas a essa ordem missionária. No mesmo ano, os Carmelitas Descalços de Pernambuco tiveram o mesmo destino e, a partir de 1830, também os Capuchinhos da mesma região foram afetados por essa política restritiva. A crise das ordens religiosas se agravou com o passar dos anos e, enquanto algumas congregações sumiam, outras foram obrigadas a vender seus próprios bens para sobreviver à difícil situação de crise, que era, também, de natureza econômica. A ação decisiva no 
confronto com as congregações religiosas acontece em 1855 quando José Tomás Nabuco, ministro da justiça, emitiu um aviso que proibia a aceitação de noviços nas ordens religiosas do Brasil. Os efeitos dessa medida foram muito relevantes. Os Franciscanos, que depois da supressão dos Jesuítas, em 1759, retomaram uma parte das missões da Companhia de Jesus, passaram a atravessar uma crise profunda, devido principalmente à sua diminuição numérica. Paralelamente a esta luta conduzida contra as ordens religiosas existentes no Brasil, o governo imperial concedia permissão a outras congregações para entrar em seu território nacional. Esta política era, em parte, coerente com a sua interpretação exclusiva dos direitos do padroado (só o governo imperial poderia decidir o destino e a composição da Igreja brasileira), mas, por outro lado, permitia o enfraquecimento das ordens religiosas consideradas muito independentes, sem privar-se da presença e da obra missionária em setores importantes como o da assistência e o da educação. Deste modo, chegaram quatro congregações que tiveram um papel fundamental na história da Igreja brasileira contemporânea: os Capuchinhos italianos, em 1825; os Jesuítas, em 1842, além dos Lazaristas e dos Salesianos (AZZI, 1982b). A presença missionária no Brasil constituiu, como em todas as realidades eclesiásticas de origem colonial, um elemento importante da estrutura eclesiástica que, adaptando-se à nova situação nascida depois da independência, construiu progressivamente a Igreja nacional brasileira contemporânea. A Igreja e o movimento missionário reencontraram novo vigor com o fim do Império e o advento da República. Em 15 de novembro de 1889, Manuel Deodoro da Fonseca, no comando do exército, se revoltou contra o poder imperial, obrigando Pedro II a renunciar ao trono. Proclamada a República, uma das primeiras reformas foi justamente a separação entre Igreja e Estado, o que se torna lei antes da promulgação da nova Constituição Federal de 1891. Em 7 de janeiro de 1890 foi então promulgada a lei que fornecia o quadro jurídicopolítico no qual aconteceria a renovação da Igreja e do movimento missionário brasileiro. Foi estabelecida a completa separação entre Igreja e Estado, sendo decretada a abolição do padroado. A lei garantiu a liberdade de culto, aboliu as subvenções para todas as crenças religiosas, reconheceu a personalidade jurídica das comunidades religiosas e aboliu todas as festas religiosas, à exceção do domingo. Na Constituição Republicana de 1891, reafirmam-se a separação entre Estado e Igreja e o fim do padroado. A Igreja estava livre e independente dentro de um Estado republicano que, por sua vez, estava livre de qualquer vínculo religioso. $O$ Estado não tinha mais obrigação de assalariar os religiosos, nem de apoiar economicamente as Igrejas, com exceção das missões, já que estas eram consideradas um importante elemento de estímulo para o progresso do país. Os edifícios religiosos eram isentos de taxas. Nas escolas, foi permitido o ensino religioso. Estas mudanças aconteceram durante o pontificado de Leão XIII que, ainda que não fosse favorável à nova Constituição Republicana, percebeu que a nova situação política e a nova ordem legislativa republicana permitiam à Igreja suficiente liberdade de ação e oportunidades de desenvolvimento. $O$ pontificado 
de Leão XIII caracterizou-se por um estímulo renovador, seja do ponto de vista da concepção teológica, seja do ponto de vista eclesiástico, quanto do ponto de vista diplomático. Esta mudança ocorrida na Igreja Católica durante o pontificado de Leão XIII coincide com o começo de um período de profunda renovação, estrutural e substancial da Igreja brasileira, dando início a uma nova fase e caracterizando de modo indelével toda a sua história futura. Este foi o panorama histórico que caracterizou a renovação da Igreja brasileira e o desenvolvimento do movimento missionário brasileiro até o final do século XIX.

\section{A renovação da Igreja e do movimento missionário no Brasil}

O revigoramento da instituição eclesiástica foi muito importante, e permitiu que o movimento missionário e a Igreja Católica ganhassem nova força ${ }^{1}$, ocupando espaço central nas importantes transformações sociais e culturais do fim do século XIX e início do século XX. A partir das últimas décadas do século $\mathrm{XIX}$, o movimento missionário teve um forte incremento. As missões se tornaram uma parte importante e determinante da Igreja, fundamental para a sua participação na criação da sociedade brasileira, com uma grande influência nos âmbitos religioso e cultural. Às congregações historicamente presentes no Brasil (Beneditinos, Capuchinhos, Carmelitas, Dominicanos, Franciscanos, Jesuítas e Lazaristas) juntaram-se, a partir de 1880, outras numerosas congregações missionárias. Em 1883, chegaram os Salesianos que, com ideias renovadoras na área da educação, dedicavam-se aos jovens carentes, filhos de escravos beneficiados com a Lei do Ventre Livre e jovens imigrantes italianos que vinham tentar a sorte no Brasil. Em 1894, chegaram os Redentoristas, fundando vários estabelecimentos missionários nos principais lugares de peregrinação do país: Aparecida e Belo Horizonte, em 1900; Rio de Janeiro, em 1903; Campinas, em 1904; Penha, em 1905; Curvelo, em 1906; e Campos, em 1923. Os Missionários do Sagrado Coração de Steyl começaram a sua obra em 1895. Em 1896 chegaram, no Rio Grande do Sul, os Missionários de São Carlos/Scalabrinianos². Entre 1896 e 1899, começam as missões da ordem Premonstratense, dos Irmãos Maristas e dos Agostinianos. Este fluxo missionário se acentuou ainda nos primeiros decênios do século XX, com a chegada de numerosas congregações: em 1901, os Salvatorianos; em 1902, os Missionários de Notre-Dame de la Salette; em 1903, os padres do Sagrado Coração e os Barnabitas; em 1907, os Irmãos das Escolas Cristãs; em 1910, os Estigmatinos, os Missionários da Sagrada Família e a Congregação dos Espiritanos; em 1911, os Passionistas e os Missionários do Sagrado Coração; em 1912, os Missionários de Notre-Dame de Sion. O movimento se interrompe durante a Primeira Guerra Mundial, mas volta com outra vivacidade em 1919, com a chegada dos Servitas; depois com os Mercedários e os Camilianos, em 1922; com os Missionários de Picpus, em 1925; com os missionários de São Francisco de Salles e os Sacramentinos, em 1926; e com os Maronitas, em 1930. 
Deste breve excursus histórico, resultam claros alguns pontos fundamentais:

O período Imperial: A) Condicionada por uma interpretação rígida do Padroado, a Igreja depende do poder monárquico. É uma Igreja ainda extremamente ligada e condicionada ao poder estatal e que, neste período histórico, foge do controle da hierarquia romana. B) A Igreja Católica vive um período de grave crise que termina somente com o advento da República. C) A crise da Igreja coincide com a crise das congregações religiosas, que viveram um lento e inexorável declínio até o advento da República.

O período Republicano: A) Com a República, tem início um período de renascimento da Igreja Católica, que se concretiza num profundo processo de reorganização e reestruturação. B) Nesta fase, o movimento missionário retoma sua grande importância, o que contribui para a formação e reestruturação da Igreja brasileira. C) Essa retomada coincide com o pontificado de Leão XIII, que se caracteriza por uma visão renovadora da Igreja e do seu papel nos planos social, diplomático e cultural. D) O reflorescimento e a reorganização da Igreja neste período guardam relação com as profundas mudanças sociais e culturais referentes à sociedade brasileira contemporânea.

Trata-se de uma Igreja que passa por um período de profunda crise e que, entre os últimos decênios do século XIX e os primeiros do século XX vê mudar a sua morfologia, tornando-se uma Igreja cada vez menos composta de um clero local e em que cada vez mais prevaleciam religiosos estrangeiros e missionários.

\section{Transformações sociais entre final do século XIX e começo do século $X X$}

As modificações que aconteceram no Brasil nas últimas décadas do século XIX e no começo do século XX foram rápidas e profundas, mudando o país não apenas no plano demográfico, como também econômico, político, social, cultural e religioso. Quando em 13 de maio de 1888 cerca de um milhão e meio de escravos ${ }^{3}$ se libertaram do seu vínculo de dependência pessoal, o quadro geral no qual a Igreja e os missionários operavam mudou profundamente. A substituição da mão de obra escrava tornou-se um problema fundamental para o mundo econômico brasileiro. Foram os imigrantes que ofereceram a resposta ao problema. Porém, já desde o começo do século XIX, através do sistema de pequenas propriedades, instaladas no interior de núcleos coloniais, o Brasil adotou uma política de imigração, atraindo, sobretudo, alemães. Na região do Rio de Janeiro se encontravam os suíços, em Nova Friburgo, (1818) e os alemães em Petrópolis (1844) e Teresópolis; na região do Rio Grande do Sul moravam os alemães, em São Leopoldo, (1824). No final do século XIX o fluxo de imigrantes interessou também Santa Catarina, Paraná, São Paulo, Espírito Santo (cf. BETHEL, 1976; ROCHE, 1968; CAVATI, 1973). Um dos primeiros missionários scalabrinianos, o padre Colbacchini, descreve esse fenômeno que ele observa na região de São Paulo: 
Foi em 1879 que teve início a primeira colônia, formada por 60 famílias mantovanas, trazidas pelo Sr. Antonio Leme da Fonseca para a sua fazenda localizada em Monte Serrat, ao longo da ferrovia Ituana, em substituição aos escravos no cultivo do café. Imediatamente após, o seu exemplo foi seguido por alguns outros e o próprio Governo da Província implantou, nas cercanias da cidade de São Paulo, as colônias de S. Ana, São Caetano e São Bernardo, perfazendo juntas um total de 150 famílias $^{4}$.

O grande fluxo imigratório que aconteceu entre final do século XIX e início do século XX transformou a fisionomia social e cultural do Brasil. Para se ter uma ideia do impacto imigratório nesse período, entre 1870 e 1930, ingressaram no Brasil mais de cinco milhões de imigrantes. A partir de 1824, identifica-se o início da imigração de colonos alemães para o Sul do Brasil (concentração inicial em São Leopoldo, Rio Grande do Sul) (cf. ROCHE, 1969). Em 1847, os imigrantes alemães começam a instalar-se também no Espírito Santo. Em torno a 1870 começa o fluxo da imigração italiana, que se concentra em São Paulo, Minas Gerais e Rio Grande do Sul. Em 1880 identifica-se o começo da imigração árabe (apesar de poderem ser encontrados registros anteriores sobre a entrada no país de imigrantes árabes, mas é a partir deste momento que o fluxo migratório aumenta). Em torno do ano de 1890 inicia-se a imigração espanhola, que se concentra, sobretudo, na região do Rio de Janeiro. Em 1908 começa a imigração japonesa em São Paulo. Os vários censos da época demonstram o crescimento da população; 9.930 .478 (primeiro recenseamento geral do Brasil em 1872); 17.438.434 (censo demográfico de 1900); 30.635 .605 (censo demográfico de 1920); 41.236 .315 (censo demográfico de 1940) ${ }^{5}$.

Os scalabrinianos são autores de uma importante reflexão sobre a migração no Brasil. Esse trabalho de reflexão, por um lado, nos fornece informações interessantes e, por outro, nos permite apreciar como o fenômeno migratório é considerado parte integrante da memória coletiva desta congregação. Na sua Storia della Congregazione Scalabriana, o padre scalabriniano Mario Francesconi descreve o fenômeno migratório no Brasil como introdução ao terceiro volume do seu trabalho:

Ao longo do decênio 1875-1885 ingressaram no Brasil entre 20 e 30 mil imigrantes ao ano; em 1886, entraram 33.486; já em 1887, ano que sinaliza praticamente o fim do regime escravista, o número se elevou para 130.056 e, em 1888, ano da abolição, chegaram 133.253 imigrantes. Em 1891, as entradas superaram a cifra dos 200 mil. Os que chegaram entre 1887-1891 representaram 14\% de toda a imigração. Em 1895 ingressaram 165 mil e, posteriormente, até a data de 1914, a média anual decresceu para 60 mil, porém, com 
momentos de pico, sobretudo entre os anos de 1910-1913, tendo este último ano alcançado o montante de $190 \mathrm{mil}$ ingressos (FRANCESCONI, 1975, vol. III, p.5).

\section{Igreja, missões e pastoral com os imigrantes}

Se, por um lado, as grandes imigrações iniciadas no fim do século XIX representam um fator de grande mudança para a sociedade brasileira (investindo de modo maciço em regiões inteiras do país), por outro lado, a imigração se traduz em um desafio fundamental para a Igreja Católica. Pelo estudo das fontes ${ }^{6}$, torna-se evidente a centralidade que a presença dos imigrantes assume, seja na reflexão sobre a realidade eclesiástica, seja sobre o significado da evangelização e a responsabilidade pastoral da Igreja ${ }^{7}$. A própria relação entre Igreja Católica e fenômeno migratório torna-se um elemento fundamental da história social, eclesiástica e cultural do Brasil, sobretudo no fim do século XIX e início do século XX. A Igreja Católica brasileira, que havia acabado de sair de um período de grave crise e estava em fase de profunda reforma e reestruturação, andava recuperando suas energias e querendo retomar seu papel central na organização da sociedade, da cultura, da moral do país. Este objetivo passava inelutavelmente pelo cuidado pastoral dos imigrantes. A centralidade do fenômeno migratório na reflexão eclesiástica se manifesta claramente na Pastoral Coletiva de 1890, que foi também a primeira na história da Igreja brasileira. Neste documento, Dom Antônio Macedo Costa lamenta a "deficiência de sacerdotes", insuficientes para cuidar da grande massa de imigrantes ${ }^{8}$. Este é o grande problema enfrentado pela Igreja brasileira nessa segunda metade do século XIX, sentido pelo clero brasileiro e pelos religiosos estrangeiros no Brasil.

\section{Jesuítas, scalabrinianos e o apostolado com os imigrantes}

Entre os primeiro a responder concretamente a essa necessidade pastoral está a Companhia de Jesus. Em 1842, os jesuítas missionários espanhóis, na Argentina, entram em conflito com o ditador Rosas que, em 22 de março 1842, emitiu um decreto ordenando a expulsão dos padres missionários. Em 1849, para responder à necessidade pastoral dos imigrantes alemães no Brasil, começaram a chegar jesuítas de fala alemã a São Leopoldo e outras cidades do interior gaúcho. Os jesuítas, por sua atividade missionária secular (ainda que interrompida pela supressão da Companhia) e por sua participação direta na colonização do território, tornam-se um ícone da presença católica no Brasil. Eles mesmos se apresentam como sendo parte integrante da história deste país e, na própria reconstrução histórica da sua participação na fundação das principais cidades brasileiras, destacam as atividades de exploração em território brasileiro e o tributo dos mártires que a Companhia pagou no seu esforço de evangelização'. É justamente em virtude da importância histórica da presença jesuíta no Brasil que resulta extremamente interessante o fato de que o retorno da Companhia de Jesus 
tenha sido marcado pela nova orientação do trabalho missionário, o qual esteve voltado, em grande parte, à pastoral com os imigrantes. Nas crônicas sobre a missão no Rio Grande do Sul, percebe-se que a chegada de missionários católicos nesta área fazia-se "necessária", em virtude da presença dos protestantes que, desde a primeira metade do século XIX, vinham sendo acompanhados por seus próprios pastores. Como relata o padre jesuíta Ambros Schup em 1912: "Estamos no ano 1844. [...] A colônia de São Leopoldo contava na época com 5.250 almas, praticamente tanto protestantes quanto católicos. Os protestantes já contavam com seus próprios religiosos alemães, os católicos ainda não (SCHUPP, 2004, p. 23). [...] Já em 1824 encontravam-se em São Leopoldo um pastor protestante, João Jorge (Johann Jörg), a quem o presidente José Pinheiro mandava pagar uma subvenção de $200 \$ 00$, portanto, o mesmo que percebiam os religiosos do país" (Idem, p. 23, em nota). A atividade dos missionários protestantes faz parte dos "Elementos Hostis" identificados como obstáculos para a obra da missão e para a presença católica no Rio Grande do Sul: "A carência de instrução religiosa por longos anos acarretou, como é compreensível, uma extrema ignorância em questões religiosas. Essa situação foi aproveitada, primeiramente, por emissários das várias seitas norte-americanas, para semear sua funesta seara no chão negligenciado" ${ }^{10}$. O padre jesuíta observa que foi fundamental o aporte dos religiosos de "fala alemã", que chegaram para coadjuvar e substituir os primeiros padres de origem espanhola ${ }^{11}$. Em 1848, fechadas na Alemanha e Áustria várias casas jesuítas, o geral da Companhia de Jesus, Roothhaan, comunicou ao padre Boworoski, provincial da província de Galícia, a decisão de enviar alguns dos padres sem função para a missão do Rio Grande do Sul. O elemento linguístico se manifesta aqui em toda a sua importância, deixando entender como as diferenças culturais tinham grande relevância no universo religioso dos imigrantes ${ }^{12}$. Depois dos jesuítas, outros missionários chegaram ao Brasil com o objetivo de desenvolver uma pastoral com os imigrantes. Entre eles se destacam os scalabrinianos, os que mais se especializaram nesse apostolado. Nascida especialmente para se ocupar da pastoral com os imigrantes, a Congregação Missionária de São Carlos (os scalabrinianos) é fruto da reflexão que surge dentro da Igreja Católica, durante a segunda metade do século XIX. O fundador da congregação, Giovanni Battista Scalabrini, representa uma das figuras mais interessantes e ativas do catolicismo europeu do fim do século $\mathrm{XIX}^{13}$. Suas origens e a sua formação de sacerdote, advindas da região norte da Itália, foram certamente importantes para a compreensão do fenômeno migratório e para a elaboração da ideia de missão a serviço dos imigrantes. O mesmo Scalabrini escreve que a inspiração lhe veio, um dia, na estação de Milão, repleta de imigrantes "filhos da miséria e do trabalho" (SCALABRINI, 1887) ${ }^{14}$. As grandes cidades do norte da Itália, como Turim e Milão, são centros de chegada e de passagem dos imigrantes. Porém, no geral, todo o nordeste italiano é uma terra de migrantes, com milhares de camponeses pobres que abandonam a própria terra em busca de fortuna nas regiões europeias do norte ou nos países além-oceano. Monsenhor Scalabrini conhece bem o problema 
das migrações e, em particular, conhece aquele povo de emigrantes da Itália do norte que povoará, até o fim do século XIX, o sul do Brasil. Da documentação examinada percebem-se, por um lado, as perplexidades de Scalabrini ao iniciar e organizar as missões no Brasil, e, por outro, as preocupações do clero local de origem estrangeira, sobretudo italiana, que solicita a chegada de missionários. Em 1886, o sacerdote Pietro Colbacchini informa Roma sobre a "preocupante" situação e sobre as necessidades da vida religiosa dos imigrantes italianos na região de São Paulo ${ }^{15}$. Notícias sobre a difícil situação dos imigrantes chegavam também de outras regiões do Brasil. Desta situação também foi informado Monsenhor Geremia Bonomelli ${ }^{16}$. É exatamente a Bonomelli que o padre Marcellino Moroni d'Agnadello, sacerdote da região do Espírito Santo, escreve em 5 de dezembro de 1886, narrando o difícil "estado dos colonos emigrados da Europa no Brasil". Em 28 de março de 1887, os mesmos imigrantes italianos do Paraná dirigiram uma carta a Leão XIII, pedindo ajuda missionária. A ideia de mandar os missionários para os imigrantes no Brasil chega ao Vaticano e, em maio de 1887, Monsenhor Antônio Agliardi escreve à Propaganda Fide sobre o projeto de fundar, na Lombardia, um colégio para prover de missionários os imigrantes italianos no Brasil. Em 19 de julho de 1887, o reverendo Pietro Ambrogio Mazza, da diocese de Cremona, escreve à Propaganda informando sobre a situação de "relaxamento" religioso dos imigrantes italianos no Rio de Janeiro. Em 25 de janeiro de 1889, padre Marcellino Moroni d'Agnadello comunica que também Santa Teresa tem necessidade de sacerdotes para os imigrantes, que conheçam a sua língua e os seus costumes. A questão da língua se revela como um elemento fundamental para esse tipo de obra missionária; frequentemente são os mesmos imigrantes que se dirigem a Roma para ter sacerdotes que os compreendam e falem a sua língua, ou venham da mesma região ${ }^{17}$.

Inicialmente, o fundador dos scalabrinianos não se declara favorável ao envio dos seus missionários ao Brasil, já que, segundo Scalabrini, a situação da Igreja brasileira ainda era muito complicada para efetuar esse tipo de obra de apostolado. Em 14 de dezembro de 1889, ele "rechaça o Memorial dos colonos italianos" e escreve à Propaganda sobre a sua perplexidade e, já que "não acredita que seja prudente" mandar os seus missionários, remete a decisão às mãos da Propaganda Fide ${ }^{18}$. Na verdade, a partir de 1887-88, Scalabrini começa a pensar no envio de missionários ao Brasil como demonstra uma carta do padre Rolleri (29 de agosto de 1888) ao sacerdote Hengesch, na qual se pergunta, em nome do fundador, de poder haver em Piacenza um bom sacerdote de língua alemã: "para enviar ao Brasil em favor de uma colônia de bons alemães, os quais desejam muito ter um sacerdote que falasse a sua língua". Pode-se supor que a cautela de Scalabrini fosse devida ao tipo de missão que ele tinha em mente para a América do Sul e, em particular, para o Brasil. Uma obra de evangelização entre os imigrantes italianos que respeitasse os particularismos culturais e, possivelmente, reforçasse as ligações patrióticas com a Itália. Um dos requisitos que Scalabrini tinha por fundamental para realizar a missão no Brasil era dar uma 
ampla autonomia aos seus missionários, que não deviam depender das paróquias locais. Uma iniciativa deste tipo devia ser bem ponderada e motivada. Fazia-se necessário, não simplesmente o aval do Vaticano, mas preparar a hierarquia local para a aceitação da nova Congregação missionária. Em 15 de novembro de 1887, Leão XIII tinha acolhido a solicitação de Scalabrini, concedendo a liberdade de ação que ele pedia para os seus missionários:

\footnotetext{
Quanto ao Brasil, se acrescentará que os próprios bispos deleguem diretamente aos missionários acima mencionados os devidos poderes, sem fazê-los depender das paróquias e dos párocos, separando, até mesmo, se necessário for, o território habitado pelos colonos italianos daquele da paróquia, erigindo paróquias separadas que ficarão a cargo dos próprios missionários ${ }^{19}$.
}

Em 25 de novembro de 1887, é publicado o decreto pontifical que aprova a criação da Congregação dos Missionários para os Emigrantes, que assume o nome de Congregação dos Missionários de São Carlos ou Scalabrinianos ${ }^{20}$. Em 10 de dezembro de 1888, Leão XIII envia aos bispos da América a carta apostólica Quam Aerumnosa na qual apresenta oficialmente a nova Congregação e manifesta o interesse de Roma para o problema da emigração ${ }^{21}$.

Em 19 de julho de 1895, Scalabrini envia ao Brasil o padre Brescianni e o padre Faustino Consoni que desenvolvem a sua atividade pastoral no Paraná, entre os italianos, os brasileiros e os poloneses ${ }^{22}$. Mas já desde 15 de fevereiro de 1895, o padre scalabriniano Giuseppe Marchetti tinha fundado, em São Paulo, um Instituto para meninos abandonados, no bairro do Ipiranga ${ }^{23}$. O nascimento das missões scalabrinianas no Brasil é um sintoma de uma nova ideia de missão. Uma missão que dá importância primordial ao elemento cultural e linguístico (como já havia feito a Companhia de Jesus em São Leopoldo), e que põe evidentes problemas do ponto de vista das relações com a Igreja local, uma vez que os missionários scalabrinianos se propõem a trabalhar independentemente da jurisdição diocesana ${ }^{24}$.

\section{Missão e diversidade cultural: as novas perspectivas do apostolado com os imigrantes}

A importância do fenômeno migratório influenciou de modo substancial ao povo dos fiéis destinatários da mensagem da Igreja Católica. A chegada de italianos (de regiões profundamente diferentes entre si do ponto de vista cultural) ${ }^{25}$, de alemães, espanhóis, suíços, russos, poloneses, ucranianos, japoneses, armênios, libaneses e outros cristãos do Oriente Médio transformou o panorama social, cultural e religioso no qual se construía a nova realidade eclesiástica (ROSOLI, 1987). O cristianismo brasileiro conheceu, a partir deste período, a variedade confessional do velho mundo mediterrâneo. Chegaram fiéis de Igrejas 
"ortodoxas", como a russa e a ucraniana, e fiéis das Igrejas católicas de rito oriental, os uniatas. Trouxeram para o Brasil os rituais litúrgicos e as tradições religiosas das antigas igrejas orientais, melquita, armênia, maronita. Um aspecto relevante deste fenômeno foi a chegada de um catolicismo variado, resultado das várias tradições religiosas dos imigrantes católicos europeus. O catolicismo brasileiro, fruto da tradição católica ibérica, e caracterizado por aquilo que Hoornaert define como cristianismo moreno (HOORNAERT, 1991), pois entrou em contato com uma multiplicidade de cultos e devoções trazidos pelos imigrantes (poloneses, italianos, tiroleses, etc). Os imigrantes chegaram trazendo como patrimônio cultural formas de religiosidade e crenças típicas do seu lugar de origem, seus próprios hábitos e ritos religiosos. As tradições e os elementos culturais religiosos tinham nessas comunidades um papel essencial na conservação da identidade cultural. Em 1904, o padre Bruno da Guillonay descreve o apego dos colonos italianos do Rio Grande do Sul às próprias usanças religiosas:

À exceção de alguns emigrantes que residem nas cidades, é
preciso reconhecer que os 300 mil italianos que se encontram
no Rio Grande do Sul permaneceram, até o presente
momento, muito fiéis à sua religião e às práticas religiosas,
sempre que lhes é facultada esta possibilidade. Percebe-se
que sentem grande necessidade das festas religiosas ${ }^{26}$.

Antonio Galioto descreve a importância da vida religiosa entre os imigrantes italianos, indicando, como centro da vida econômica, política, social e cultural, a igreja (GALIOTO, 1987-1990, p. 293-312). A igreja era, ao mesmo tempo, lugar físico de reunião e símbolo de integração a uma comunidade com tradições culturais e linguísticas precisas. Este fenômeno se desenvolveu e se manifestou de modos diferentes nos centros urbanos e nas zonas menos urbanizadas, contribuindo para um enriquecimento enorme da esfera cultural e religiosa. Esse dado é observado também pelo padre Bruno da Guillonay:

Tendo chegado a um país onde só havia florestas virgens, obrigados a prover o necessário e organizar-se minimamente, os imigrantes e suas famílias acabaram deixando totalmente de lado as coisas de Deus. Mas hoje, em todas as paróquias, já existe uma igreja, via de regra bonita, e por vezes muita linda. Além dessa igreja, construíram um grande número de outras pequenas capelas, todas muito aconchegantes nas quais se reúnem aos domingos para rezar juntos, tendo em vista as distâncias que os impedem de ir até a igreja paroquial ${ }^{27}$.

A igreja e as capelas fazem parte de um processo de sacralização do espaço geográfico dos colonos, símbolos da memória religiosa, elementos de um universo sacro familiar. Ajudam a unir a comunidade, a consolidar os elementos 
morais que servem como pontos de referência no universo relacional da vida cotidiana.

$\mathrm{Na}$ crônica do padre Ambros Schupp, sobre a missão jesuíta entre os alemães do Rio Grande do Sul, o autor narra que os jesuítas "mandavam vir" da Alemanha livros para instruir seus paroquianos, "entre eles o excelente Goffiné, o muito apreciado Martin Kochem ${ }^{28}$, legendas de santos, etc." (SCHUPP, 2004, p. 143). O elemento linguístico representa um componente fundamental da identidade cultural imigrante; ele se encontra em um nível mais consciente e culturalmente sofisticado em produções literárias, mas também nos atos da vida quotidiana, nas relações intrafamiliares e intracomunitárias. A vivacidade cultural da migração italiana no Brasil é testemunhada por uma interessante produção literária em idioma italiano; por um lado, manifestação de uma cultura persistente e resistente (a cultura nativa) e, por outro, de um interessante fenômeno de hibridismo cultura $^{29}$. Outro interessante aspecto dessa atividade literária foi a produção de uma literatura dialetal que utiliza uma língua chamada talian (tratase de uma língua dialetal, com a prevalência do dialeto vêneto, e elementos de outros dialetos italianos presentes no Rio Grande do Sul, mais vocábulos da língua portuguesa e alterações fonéticas) ${ }^{30}$. 0 idioma nativo está relacionado com a memória cultural de antes da migração, como narra muito bem Darcy Loss Luzzato, escritor brasileiro de origem italiana, (ou, melhor dizendo, vêneta), que escreve em "idioma" vêneto ${ }^{31}$. Como explicam Rovilio Costa e Antônio Hohlfeldt, a persistência do idioma ou do dialeto de origem foi fortalecida pela prática religiosa e pelo trabalho dos missionários ${ }^{32}$. Na segunda metade do século XIX, os missionários católicos (jesuítas, franciscanos, scalabrinianos) desenvolvem uma pastoral que respeita a língua nativa dos imigrantes, fortalecendo as particularidades culturais das diferentes comunidades imigradas. Essa particular atenção para a cultura e o idioma dos imigrados é ditada, originariamente, pela preocupação de preservar a fé católica dos imigrados, ameaçada pela diminuição do sentimento religioso: "Quando a necessidade preme, quanto antes for atendida, muito melhor será, evitando que esta gente ainda não caída em desgraça, não se acostume a viver sem religião ou, pior ainda, sem sentir sua necessidade, como já aconteceu em muitos lugares"33. Outra preocupação nasce do trabalho das "seitas protestantes" ou do "espiritismo, que põe em prática as suas bruxarias tanto nas casas dos de alta consideração como nas choupanas dos pobres" (SCHUPP, 2004, p. 267). No caso dos imigrantes italianos, mais do que o idioma nacional, assume importância fundamental o conhecimento da cultura e do dialeto regionais. As tradições dessa população de fiéis são variadas e, às vezes, muito distantes das tradições e da cultura dos missionários, que podem chegar de outra região da Europa (mesmo sendo todos católicos e, frequentemente, da mesma nação). Assim como acontece em Santa Teresa (Espírito Santo), onde o cônsul italiano em Vitória, Rizzetto, acha que os poucos resultados conseguidos pelos padres Capuchinos se devem, provavelmente, ao fato de que os missionários sejam sicilianos e os imigrantes vênetos e trentinos, 
"porque sendo os frades sicilianos, não conseguiram, até o momento, inculturarse com uma população que apenas fala o dialeto vêneto [...] constata-se que sua atuação junto aos colonos, até o momento presente, deixa a desejar" (RIZZETTO, 1905, p. 10). Riolando Azzi lembra que "uma das preocupações fundamentais do bispo Scalabrini, durante a etapa de Unificação Italiana, fora no sentido que não se operasse uma separação entre o sentimento religioso e o sentimento patriótico, de tal forma que a população fosse obrigada a fazer sua escolha entre a Fé ou a Pátria" (AZZI, 1987, p.107). No seu primeiro e mais importante escrito sobre a emigração, Scalabrini trata o problema da migração conjuntamente ao problema das colônias, e afirma:

\begin{abstract}
Como sabemos, a Itália não possui colônias e não apresenta hoje condições de adquiri-las, mesmo após ter sido, durante séculos, rainha dos mares. Poucas nações possuem, de fato, tradições coloniais como a Itália. [...] Entretanto, sem ter que empreender desgastantes conquistas, a ltália poderia encontrar na América um vasto campo para o desenvolvimento de suas colônias, as quais, mesmo não dependendo politicamente da mãe-pátria, como ocorrecomas inglesas efrancesas, poderiam, contudo, servir de grande vantagem para o desenvolvimento do seu comércio e para exercer a sua legítima influência (cf. SCALABRINI, 1887, cap. V e VII).
\end{abstract}

Consciente da importância da religião entre as multidões dos emigrantes, Scalabrini acredita que o esforço conjunto das forças católicas e governativas para proteger os migrantes italianos poderia superar as divisões que existem na Itália entre a Igreja Católica e o Governo italiano (questione romana). Essa ideia de Scalabrini é uma versão católica daquele pragmatismo que na época caracterizava a política das potências europeias. A própria França, republicana e berço das leis anticlericais, fazia da proteção dos cristãos orientais e dos missionários católicos no Império Otomano e na China Imperial, um importante instrumento de influência política (cf. RUSSO, 1999 e SAAÏDIA, 2005). As afirmações de Scalabrini, que podiam seduzir alguns setores católicos e políticos italianos, não podiam deixar indiferentes o mundo político e a imprensa dos estados americanos, nos quais o imaginário coletivo estava criando a sua própria retórica nacionalista. Em 1904, por ocasião da viagem de Scalabrini ao Brasil e à Argentina, perplexidades e reações se manifestaram abertamente na imprensa brasileira. Em 16 de julho de 1904, O Estado de São Paulo escrevia:

Poucos dias faz chegou aqui o bispo de Placência, Itália. Um bispo como os outros, aos quais estamos habituados enviar os importunos a lamentar-se? Não. Este é um pouco diferente. Além de ser muito íntimo ao Papa Pio $X$, é fundador da Congregação de São Carlos, consta que 
vem com uma importante missão do governo italiano, daquele mesmíssimo governo sacrílego que, por ter entrado em Roma, golpeou com canhões e baionetas e foi excomungado por um dos sucessores de São Pedro. [...] Os missionários modernos se interessam de assuntos mais práticos, preocupam-se dos problemas industriais e políticos. Aventuram-se ainda pela Ásia, África e América, mas carregam debaixo dos braços o fuzil carregado e a mala de mercadorias para determinar as zonas de influência das nações colonizadoras, consagrando-se a seu serviço (PESTANA, 1904; cf. COSTA, 2004).

Com personagens como Leão XIII, Giovanni Battista Scalabrini, Geremia Bonomelli, Peter Paul Cahensly ${ }^{34}$ e Francesca Saverio Cabrini ${ }^{35}$, o fenômeno das migrações passava a fazer parte da reflexão pastoral da Igreja Católica. No mesmo período, para o Brasil e para a Igreja brasileira tornava-se uma questão fundamental. O novo tipo de missão que os jesuítas e os scalabrinianos desenvolvem, dando grande importância ao elemento linguístico e cultural, representa uma importante novidade, mas abre caminho para grandes problemas nas relações com o mundo político local, com a Igreja local e com o nacionalismo sul-americano. No novo imaginário coletivo nacionalista, em formação no Brasil, não parecia haver espaço, ao menos no momento, para a italianidade dos imigrantes invocada por Scalabrini.

\section{Notas}

1- Em 1889 havia no Brasil somente 12 dioceses. Leão XIII criou duas províncias eclesiásticas: São Salvador da Bahia (sete dioceses) e Rio de Janeiro (nove dioceses). Pio X aumentou o número de arquidioceses que chegaram a sete. No período de Bento XV e Pio XI, aumentaram as províncias eclesiásticas que chegaram a 17 e as dioceses subiram para 72, mais 19 prelaturas nullius e 2 prefeituras apostólicas.

2 - Mas eles já estavam presentes no Espírito Santo (1888-1895) e no Paraná, aonde também chegaram em 1888.

3 - Segundo o censo de 1872. Muito provavelmente o número real excedia esta quantidade. 4 - ACMSCR (Archivio Congregazione Missionaria di San Carlo, Roma), 356/14, Relazione del padre P. Colbacchini spedita con lettera di accompagnamento a Mons. P. Spolverini, 19-6-1889.

5 - Sobre a colonização italiana ver DE BONI (1987-1990). Sobre a imigração japonesa ROCHA NOGUEIRA (1984). Mais em geral sobre a imigração no Brasil ver BASTOS DE ÁVILA (1956). Os censos são citados no site do IBGE: Brasil 500 anos de povoamento, Site do IBGE, http:// www.ibge.gov.br/brasil500/index2.html.

6 - Nos arquivos do Vaticano e, em particular, no arquivo da Congregação de Propaganda Fide.

7 - Sobre esse argumento ver o interessante trabalho "Mudanças nas relações entre a Igreja, a sociedade, o estado e o povo dos fiéis" (BEOZZO, 2007).

8 - Dom Antônio Macedo Costa, Alguns pontos de reforma na Igreja do Brasil - Memória para servir às discussões e resoluções nas conferências dos Senhores Bispos (Azzı, 1982a, p. 65).

9 - Chegada ao Brasil com o primeiro governador, Tomé de Souza, a Companhia de Jesus se faz presente nesta região desde 1549. Na Bahia, os jesuítas estão presentes já no período de fundação da cidade de Salvador. Fundam o colégio de Piratininga em 1554 e participam, entre 
1560 e 1567, da fundação do Rio de Janeiro por obra de Mem de Sá. Em 1757, a Companhia contava com 631 membros no Brasil. Foi expulsa em 1759, por obra do Marquês de Pombal e Dom José I, rei de Portugal. Em 1773, Clemente XIV dissolve a Companhia. Na América Latina, a maioria das obras ficou abandonada. No Brasil, uma parte dos jesuítas foi substituída pelos franciscanos. Em 1841, quarenta anos depois da sua supressão, o Papa Pio VII restabeleceu a Ordem de Inácio em toda a Igreja.

10 - "Em primeiro lugar foram os religiosos da igreja anglicana. [...] Além dos anglicanos, entram aqui em consideração os metodistas, também procedentes da América do Norte [...] Outra seita que tenta de imiscuir-se insistentemente no estado são os assim chamados sabatistas (adventistas)" (SCHUPP, 2004, p. 265-266).

11 - Em 1869 a missão passou para a jurisdição da província alemã da congregação.

12 - Na sua narração, o padre Ambros Schupp descreve o desenvolvimento das residências e colônias residenciais dos padres alemães: colônias do Vale do Rio Sinos, a Picada Baum e São Miguel dos Dois Irmãos, a Picada dos Portugueses e São José do Hortêncio, São Leopoldo, Nova Hamburgo e Bom Jardim, Porto Alegre, as colônias do Vale do Rio Caí, Montenegro, São Sebastião, Nova Petrópolis, Bom Princípio, São Salvador, Harmonia, Feliz, Vale do Rio Taquari, Estela e Lajeado, Vale do Rio Pardo, Santa Cruz, Pelotas e Rio Grande, São Pedro de Alcântara, São Lourenço, Nonoai (SCHUPP, 2004).

13 - Foi bispo de Placência, diocese na qual entra em fevereiro de 1876. Funda a Escola das Doutrinas Cristãs, a revista Catequista Católico e, em 1889, celebra o primeiro Congresso Catequético nacional. Mas foi na pastoral com os imigrantes que o ativismo de Scalabrini deu os seus frutos mais interessantes. Em 28 de novembro de 1887, funda a Congregação dos Missionários de São Carlos, em 1889 a Associação Laica São Rafael, para a assistência aos imigrantes, e em 25 de outubro de 1895 a Congregação das Irmãs Missionárias de São Carlos.

14 - É certo que, durante a sua primeira visita pastoral à diocese de Placência, recolhera dados estatísticos sobre a emigração do Apenino, os quais evidenciaram que quase $12 \%$ dos fiéis haviam emigrado da Europa para a América.

15 - APF (Archivio Propaganda Fide, Roma), FSRC (Fondo Scritture Riferite nei Congressi), AMIP (America Meridionale dall'Istmo di Panama), vol. 15, Lettera di Colbacchini a Propaganda Fide, 12-08,1886; APF, FSRC, AMIP, vol. 15, Lettera di Colbacchini a Propaganda Fide, 29-11,1886.

16 - Bispo de Cremona, personalidade da Igreja católica também muito sensível ao problema da migração. Em 1896, Bonomelli promulgou a carta pastoral A Emigração e em 1900 fundou a Obra de assistência para os italianos emigrados da Europa, depois denominada Obra Bonomelli, que fornecia aos italianos emigrados uma assistência material e religiosa, tanto do lado pessoal quanto missionário (cf. GALLINA, 1974; MARCORA, 1983).17 - APF, FSRC, AMIP, vol. 15, Lettera di Marcellino d'Agnadello a Propaganda Fide, 5-12,1886; APF, FSRC, AMIP, vol. 15, Indirizzo degli emigrati italiani nel Paranà pel Giubileo del Santo Padre, 28-03,1887; APF, FSRC, AMIP, vol. 15, Lettera di Mons. Agliardi a Propaganda Fide, 27-05,1887; APF, FSRC, AMIP, vol. 15, Lettera di Pietro Ambrogio Mazza a Propaganda Fide, 19-07,1887; APF, FSRC, AMIP, vol. 15, Lettera di Marcellino d'Agnadello a Propaganda Fide, 25-01,1889; APF, FSRC, AMIP, vol. 15, Lettera di Filippo Vergilio, 1889.

18 - APF, FSRC, AMIP, vol. 15, Lettera di Giovanni Battista Scalabrini a Propaganda Fide, 14$12,1889$.

19 - APF, Collegi Vari, Collegi d'Italia, 1388, Lettera di mons. Jacobini a G.B. Scalabrini, 15-11-1887.

20 - Acta Sanctae Sedis, XX (1887), p.305.

21 - LEÃo XIII, “Quam aerumnosa” (em LEÃo XIII, 1889, p. 380-384).

22 - Mas já em 1887, o padre Colbacchini estava morando em Água Verde, perto de Curitiba (ACMSCR, 356/19, Lettera del padre Colbacchini al padre Mantese, 26-12-1887). Em agosto de 1888 chegaram a Curitiba o padre Domenico Mantese, o padre Giuseppe Molinari e o leigo Vittorio Gabualdi (ACMSCR, 356/20, Lettera del padre Colbacchini al padre Rolleri, 19-9-1888).

23 - Sobre o padre Marchetti (cf. FRANCESCONI, 1969). Quero agradecer o professor José Oscar 
Beozzo que me forneceu um material inédito e de grande interesse sobre este assunto.

24 - As missões scalabrinianas se desenvolveram nos lugares onde havia presença italiana: Espírito Santo (1888-1895 e 1903-1908); Paraná (Santa Felicidade, Rondinha, Campo Comprido, Umbará, Água Verde, Campo Largo, Colombo), Tibagi (1904-1911); Rio Grande do Sul (Encantado, Capoeiras [Nova Prata], Nova Bassano, Protasio Alves, Bela Vista, Anta Gorda, Esperança [Vespasiano Corrêa], Muçum, Nova Brescia, Santa Teresa, São Lourenço de Vilas Boas [Coronel Pilar], Monte Belo, Monte Vêneto [Cotiporã], Guaporé, Bento Gonçalves); além da presença no estado e na cidade de São Paulo.

25 - As mesmas reflexões podem ser feitas para outras nacionalidades: alemães, espanhóis, etc. 26 - ACMSCR, 10/5, Relazione del padre Bruno da Guillonay sugli italiani del Rio Grande do Sul a Mons. G. B. Scalabrini, 12-10-1904.

27 - ACMSCR, 10/5, Relazione del padre Bruno da Guillonay sugli italiani del Rio Grande do Sul a Mons. G.B. Scalabrini, 12-10-1904.

28 - Goffiné: beneditino alemão (1648-1719). Martin Kochem: capuchino alemão (1634-1712).

29 - Entre 1897 e 1900 foi produzida no Brasil uma série de peças teatrais em língua italiana, que foram também publicadas (cf. HOHLFELDT, 1991; GARCEZ GHIRARDI, 1985; SILVEIRA, 1976). 30 - Outro fenômeno linguístico-literário interessante, diretamente relacionado à presença dos imigrantes italianos no Brasil, foi o nascimento de uma literatura em "português-macarrônico", que imitava o português falado pelos habitantes dos bairros italianos de São Paulo: Bexiga, Brás e Barra Funda. Em 1911, Alexandre Ribeiro Marcondes Machado (Juó Bananère) começou a publicação de poemas e crônicas nessa particular forma de falar, na revista $O$ Piralho, dirigida por Oswald de Andrade, importante representante do modernismo literário brasileiro (HOHLFELDT, 1991, p. 207). Nos anos 1950-60 esse tipo de "português mal falado dos imigrantes italianos" foi transformado em samba por João Rubinato (paulistano, filho de dois imigrantes italianos de Cavárzere, província de Veneza), mais conhecido como Adoniran Barbosa. A sua canção de amor Tiro ao Álvaro (1960), magistralmente interpretada e levada ao sucesso nacional e internacional por Elis Regina, utiliza aquele típico "palavreado do povo" paulistano de ascendência italiana, constelado de erros de português.

31 - "Que coisa estranha, mais velho se torna e mais fácil fica retornar a falar o vêneto. Eh sim, diria que seria justo o contrário, porque são os velhos que se esquecem de tudo, não é verdade? Tantos anos passados sem dizer uma só palavra em vêneto e, de repente, como por milagre, se recomeça a raciocinar na língua materna, aquela que havíamos aprendido em nossas casas, como se sempre a tivéssemos falado. Acredito que da língua materna não se esqueça nunca. Ela permanece como que adormentada e, na primeira oportunidade, ela se acorda!" [tradução do original em vêneto] (LOSS LUZZATO, 1975, p.25; cf. HOHLFELDT, 1991, p. 205-212). Mais em geral sobre a literatura dialetal dos italianos do Rio Grande do Sul ver Rovilio Costa (COSTA, R., 1987, p. 256 e passim).

32 - Típico exemplo foi o sucesso de Vita e storia de Nanetto Pipetta, publicado no jornal Staffetta Riograndese de Caxias do Sul (Rio Grande do Sul) entre 1924 e 1925, que narra a vida de um jovem italiano, nascido em 1868, que decide migrar para as Américas e morre no Rio das Antas entre 1886-1888 (cf. HOHLFELDT, 1991; COSTA R, 1987; GARDELIN, 1988; GALIOTO, 1988).

33 - ACMSCR, 356/7, Lettera del padre Colbachini a G.B. Scalabrini, S. Paulo, 2-7-1889.

34 - Fundador da União de São Rafael na Alemanha.

35 - Fundadora das Missionárias do Sagrado Coração.

\section{Referências}

AZZI, Riolando. Dom Antônio de Macedo Costa - Bispo do Pará, Arcebispo Primaz (1830-1891). In: Cadernos de História da Igreja. º1, São Paulo, 1982a, p. 60-75.

AZZI, Riolando. Os Salesianos no Rio de Janeiro. V. I (1875-1884), São Paulo: Ed. Salesiana Dom Bosco, 1982b.

AZZI, Riolando. A Igreja e os migrantes. Vol. I, A imigração italiana e os primórdios da obra 
escalabriniana no Brasil (1884-1904). São Paulo: Paulinas, 1987.

BASTOS DE ÁVILA, Fernando. L'immigration au Brésil. Contribution à une théorie générale de l'immigration. Rio de Janeiro: Ed. Agir, 1956.

BEOZZO, José Oscar. Mudanças nas relações entre a Igreja, a sociedade, o estado e o povo dos fiéis. In: PAROLIN, Gaetano e LOVATIN, Agostino (ed.). L'ecclesiologia scalabriniana. Roma: Urbaniana University Press, 2007, p. 51-71.

BETHEL, Leslie. A abolição do tráfico de escravos no Brasil. Rio de Janeiro-São Paulo: Expressão e Cultura, 1976.

CAVATI, João. História da imigração italiana no Espírito Santo. Belo Horizonte: Editora São Vicente, 1973.

COSTA, Gelmino. Bem-aventurado João Batista Scalabrini. Centenário de sua visita ao Brasil e à Argentina. São Paulo: Edições Scalabrinianas, 2004.

COSTA, Rovilio. La letteratura dialettale italiana: ritratto di una cultura. In: VV.AA. Euroamericani. Vol. III (La popolazione di origine italiana in Brasile), Turin: Fondazione Agnelli, 1987.

DE BONI, Luis Alberto (org.). A presença italiana no Brasil. Porto Alegre-Torino: Fondazione Agnelli, 1987-1990.

FRANCESCONI, Mario. Storia congregazione scalabriniana. Roma: Archivio Generalizio Scalabriniano, 1975.

FRANCESCONI, Mario. Come una meteora - Padre Giuseppe Marchetti (1869-1896). Piacenza: Centro Missionario Scalabrini, 1969.

GALIOTO, Antônio. O significado das capelas nas colônias italianas do Rio Grande do Sul. In: DE BONI, Luís A. (org.). A presença italiana no Brasil. Porto Alegre-Torino: Fondazione Agnelli, 1987-1990, p. 293-312.

GALIOTO, Antonio. Don Giocondo, Vigário dela Zanta. Porto Alegre: Posenato Arte e Cultura, 1988.

GALLINA, Giuseppe. II problema religioso nel Risorgimento e il pensiero di Geremia Bonomelli. Roma: Pontificia Università. Gregoriana, 1974.

GARCEZ GHIRARDI, Pedro. Escritores de língua italiana em São Paulo (1890-1929). Universidade de São Paulo, Faculdade de Filosofia, São Paulo, 1994.

GARDELIN, Mario. Imigração italiana no Rio Grande do Sul. Fontes literárias. Porto AlegreCaxias do Sul: Est/Educs Fondazione G. Agnelli, 1988.

HOHLFELDT, Antonio. La letteratura di lingua italiana in Brasile. In: MARCHAND, JeanJacques. La letteratura dell'emigrazione. Gli scrittori di lingua italiana nel mondo. Turin: Fondazione Agnelli, 1991, p.205-212.

HOORNAERT, Eduardo. O Cristianismo moreno do Brasil. Petrópolis: Vozes, 1991.

LEÃO XIII. Leonis P. M. Acta. V. 3, Roma, 1889.

LOSS LUZZATO, Darcy. Ghen'avemo Fato Arquante... . Porto Alegre: D. C. Luzzatto ed., 1975.

MARCORA, Carlo (ed.). Carteggio Scalabrini-Bonomelli 1868-1905. Roma: Studium, 1983.

MECHAM, J. L. Church and State in Latin America. Chapell Hill: University of North Carolina Press, 1966, p. 262.

PESTANA, Paulo R. O Quirinal e o Vaticano: uma aliança contra a nacionalidade brasileira! In: O Estado de São Paulo. 16/7/1904.

RIZZETTO, R. Colonizzazione italiana nello stato di Espirito Santo (Brasile): Rapporto del cavalier R. Rizzetto, R. Console d'Italia a Vittoria - agosto 1904. In: Bollettino dell'Emigrazione. $N^{\circ} 7$, 1905, p. 10-13.

ROCHA NOGUEIRA, Arlinda. Imigração japonesa na história contemporânea do Brasil. São Paulo: Centro de Estudos Nipo-Brasileiros, 1984.

ROCHE, Jean. A colonização alemã no Espírito Santo. São Paulo: Difel/USP, 1968.

ROCHE, Jean. A colonização alemã no Rio Grande do Sul. Porto Alegre: Editora Pallotti, 1996. ROSOLI, Gianfausto (ed.). Emigrazione europee e popolo brasiliano. Roma: CSER, 1987.

RUSSO, Maurizio. Benoît XV: le pape de la paix. Aux racines du pacifisme catholique. In: PETRICIOLI, Marta e CHERUBINI, Donatella (ed.). For Peace in Europe. Institutions and 
Civil Society Between the World Wars. Bruxelas-Freiburg-Manchester: Peter Lang, 2008. RUSSO, Maurizio. Iglesia y Estado en América Latina en el siglo XIX: El Salvador entre independencia y construcción nacional. In: Crisol. Nouvelle Série, no 10, 2006, p. 167-182.

RUSSO, Maurizio. La politique de protection des intérêts chrétiens en milieu non-chrétien. In: Hummel, Hintilian e CARMesund (ed.). Patterns of the Past, Prospects for the Future. The Christian Heritage in the Holy Land. London : Melisende, 1999, p. 32-53.

SAAÏDIA, Ossila. L'anticléricalisme article d'exportation? Le cas de l'Algérie avant la première guerre mondiale. In : Vingtième Siècle. Revue d’histoire. N 87, 2005/3 (Laïcité, séparation, sécularisation 1905-2005), 2005, p. 101-112.

SCALABRINI, Giovanni Battista. L'emigrazione italiana in America. Piacenza: Tip. Dell'amico Del Popolo, 1887.

SCHUPP, Ambros. A missão dos jesuítas alemães no Rio Grande do Sul. São Leopoldo: Editora Unisinos, 2004 (O texto que utilizamos é a edição contemporânea do trabalho do padre Schupp, que foi redigido entre 1908 e 1914).

SILVEIRA, Miroel. A contribuição italiana ao teatro brasileiro. São Paulo: Quíron/mec, 1976.

\title{
RESUMO
}

Este artigo representa a primeira parte de uma pesquisa in fieri abrangendo, grosso modo, da Primeira República brasileira até a Primeira Guerra Mundial, durante os dois pontificados de Leão XIII e Pio X. O fim da escravidão, o início da imigração no fim do século XIX e a República motivam um profundo processo de reorganização e reestruturação da Igreja Católica brasileira, com a chegada de contingentes estrangeiros que transformam o panorama social, cultural e religioso e constituem uma nova realidade eclesiástica. A introdução de tradições religiosas dos imigrantes traz novas exigências pastorais quanto à assistência religiosa e material, concentrando a atenção e o debate. Ocorre a organização das missões segundo um princípio linguístico, a evangelização nos idiomas originários dos imigrantes, com fortalecimento de identidades nacionais, costumes e tradições típicas dos lugares de origem. Jesuítas, Scalabrinianos e Capuchinos são os primeiros e mais ativos nesse tipo de missão.

Palavras-chave: religião; imigração; ordens religiosas.

\begin{abstract}
This article represents the first part of an in fieri research which roughly extends chronologically from the First Brazilian Republic to World War I, overlapping with the pontificates of Leo XIII and Pius X. The end of slavery, the beginning of immigration and the Republic bring a profound process of reorganization and restructuring of the Catholic Church, with the arrival of foreigners who change the social, cultural and religious landscape, and the building of a new ecclesiastical reality. The introduction of religious traditions of immigrants introduces new pastoral demands emanating from this host of new believers and their needs in terms of religious and material assistance, drawing attention and debate to the Catholic church. Missions were organized according to a linguistic principle, and the evangelization was carried out in the language of the immigrants, which stimulated the strengthening of national identities, customs and traditions that were typical of their homelands. Jesuits, Scalabrinians and Cappuccinos were the first and the most active in this type of mission.
\end{abstract}

Keywords: religion; immigration; religious orders. 